\title{
Psychosomatic syndromes and anorexia nervosa
}

\author{
Giovanni Abbate-Daga*, Nadia Delsedime, Barbara Nicotra, Cristina Giovannone, Enrica Marzola, \\ Federico Amianto and Secondo Fassino
}

\begin{abstract}
Background: In spite of the role of some psychosomatic factors as alexithymia, mood intolerance, and somatization in both pathogenesis and maintenance of anorexia nervosa (AN), few studies have investigated the prevalence of psychosomatic syndromes in AN. The aim of this study was to use the Diagnostic Criteria for Psychosomatic Research (DCPR) to assess psychosomatic syndromes in AN and to evaluate if psychosomatic syndromes could identify subgroups of AN patients.

Methods: 108 AN inpatients (76 AN restricting subtype, AN-R, and 32 AN binge-purging subtype, AN-BP) were consecutively recruited and psychosomatic syndromes were diagnosed with the Structured Interview for DCPR. Participants were asked to complete psychometric tests: Body Shape Questionnaire, Beck Depression Inventory, Eating Disorder Inventory-2, and Temperament and Character Inventory. Data were submitted to cluster analysis.

Results: Illness denial (63\%) and alexithymia (54.6\%) resulted to be the most common syndromes in our sample. Cluster analysis identified three groups: moderate psychosomatic group (49\%), somatization group (26\%), and severe psychosomatic group (25\%). The first group was mainly represented by AN-R patients reporting often only illness denial and alexithymia as DCPR syndromes. The second group showed more severe eating and depressive symptomatology and frequently DCPR syndromes of the somatization cluster. Thanatophobia DCPR syndrome was also represented in this group. The third group reported longer duration of illness and DCPR syndromes were highly represented; in particular, all patients were found to show the alexithymia DCPR syndrome.
\end{abstract}

Conclusions: These results highlight the need of a deep assessment of psychosomatic syndromes in AN. Psychosomatic syndromes correlated differently with both severity of eating symptomatology and duration of illness: therefore, DCPR could be effective to achieve tailored treatments.

Keywords: Anorexia nervosa, Eating disorders, Psychosomatic syndromes, Illness denial, Alexithymia

\section{Background}

It is known in scientific literature that anorexia nervosa (AN) is a psychosomatic condition [1-3]. Some authors have recently highlighted the role of several factors like alexithymia [4], emotion and anger dyscontrol [5], and somatization [6] in both development and maintenance of the disorder. It has also been described a psychosomatic and somatopsychic vicious circle as underpinning AN symptomatology [7-9].

Moreover, poor interoceptive awareness $[10,11]$ - the inability of discerning the difference between somatic and emotional perception (i.e. feeling "fat" versus feeling angry)

\footnotetext{
* Correspondence: giovanni.abbatedaga@unito.it

Department of Neuroscience, Section of Psychiatry, Eating Disorders Centre, University of Turin, Turin, Italy
}

\section{() Biomed Central}

(c) 2013 Abbate-Daga et al.; licensee BioMed Central Ltd. This is an Open Access article distributed under the terms of the Creative Commons Attribution License (http://creativecommons.org/licenses/by/2.0), which permits unrestricted use, distribution, and reproduction in any medium, provided the original work is properly cited.
- is a hallmark of AN and has been recently supported by preliminary neuroscientific evidence [12].

In spite of this body of literature, there is a lack of research systematically investigating the comorbidity of psychosomatic conditions in AN [13].

The Diagnostic Criteria for Psychosomatic Research (DCPR) [14] have been proposed to deepen psychosomatic aspects. Such criteria suggest a new diagnostic frame for psychosomatic syndromes characterizing medical and psychiatric conditions to overcome the limits of the Diagnostic and Statistical Manual-IV (DSM-IV) [15] as regards somatoform disorders and to formulate a new approach for the DSM-V $[14,16,17]$. The DSM-IV chapter on somatoform disorders has been widely criticized [18]. In particular, its failure to adequately cover the clinical phenomena of somatisation and models of 
psychosomatic syndromes has been brought into question. Some authors $[18,19]$ have acknowledged that the classification of somatoform disorders is not well supported in scientific literature and that it should be widely modified. The DSM-IV [15] shows the category of the psychological factors affecting medical conditions trying to better specify the psychological aspects but it is used in a very unspecific way. This may depend on a difficulty of a categorical psychiatric instrument, as the DSM, to recognize the subthreshold aspects of psychological distress. The DCPR system offers an alternative to DSM-IV's somatoform disorders but also allows the clinician to characterize a patient's mode of perceiving, recognizing, labelling, and responding to a health status [20]. DCPR variables may occur in conjunction with any psychiatric disorder listed in the DSM-IV or with any medical disorder [18].

The DCPR have been found to be more suitable than DSM-IV [15] criteria in describing psychological distress in a variety of medical settings; moreover, the DPCR represent an instrument to get through the dichotomy organic/ functional. They also provide a biopsychosocial perspective in the most common medical conditions [14,21,22].

To date, the DPCR have been used in patients affected by gastrointestinal, cardiac, dermatological, endocrine, and neoplastic disorders; in addition, also in patients affected by somatoform disorder and in consultationliaison psychiatry [20,23-29]. In a study conducted on 347 individuals from the general population, alexithymia, type A behavior, and irritable mood were found as relatively common DCPR syndromes correlating with worse quality of life whilst demoralization and persistent somatization were common in those medically ill and not in the general population [30].

More recently, the use of the DCPR allowed to individuate in a large sample of medically ill patients the association between anxiety and psychosomatic disorders [31] and psychosomatic subtypes of major depressive disorder [32].

Studies of consultation-liaison psychiatry demonstrated that about $85 \%$ of patients showed some DCPR syndromes while $51 \%$ was found to have several associated DCPR syndromes [33].

To the best of our knowledge, in literature there is only one study, conducted by our group, that applied the four syndromes of the area "Psychological factors influencing vulnerability to illness" of DPCR to 101 Eating Disorder (ED) outpatients [13]. Since it was a preliminary study we considered only the four syndromes providing a better specification of the DSM-IV rubric of psychological factors affecting medical condition, excluding the eight factors related to somatisation. Our previous paper investigated all ED diagnoses (AN restricting subtype $[A N-R]$ and binge-purging subtype [AN-BP], Bulimia nervosa, Eating Disorder Not Otherwise Specified including Binge Eating Disorder) using the DCPR. Alexithymia was the most represented syndrome (52\% of the sample), followed by demoralization (48\%), irritable mood (40\%), and type A behavior (27\%) with the majority of the sample reporting at least one DCPR syndrome [13]. Among diagnostic categories, AN-R patients were found to show the highest frequency of psychosomatic syndromes according to the DCPR.

The aforementioned paper by Fassino and Coworkers [13] provided preliminary data on the utility of assessing psychosomatic syndromes in ED using the DCPR. It confirmed the prevalence of alexithymia, demoralization, and anger as assessed not only using psychometric measures $[4,34]$ but also as full syndromes clinically evaluated. The clinical identification of psychosomatic syndromes confirms the theoretical psychosomatic model. The latter considers psychosomatic factors as key-aspects in the pathogenesis of ED given the central role of lived corporeality and alienation from one own's body and one own's emotion $[35,36]$.

To bridge the gap between psychosomatic factors and ED we conducted this study aiming to: a) replicate and widen previous data on the prevalence of psychosomatic syndromes on AN inpatients applying all twelve criteria on a large sample; b) divide the wide and heterogeneous AN group according to the DCPR syndromes and clinical variables using a cluster analysis.

Our a priori hypothesis consisted in the identification of clusters with different prevalence of DCPR syndromes and clinical and psychosocial features.

\section{Methods}

The study population consisted of 108 AN inpatients consecutively hospitalized at the ED Centre of the University of Turin, Italy, over a period of two years. Hospitalization occurred during patients' emergency phase; according to international guidelines [37], hospitalization was needed on the bases of psychiatric and behavioral factors, including a rapid or persistent decline in oral intake or co-occurring psychiatric problems leading to medical instability, abnormalities in vital signs and laboratory tests. Moreover, patients' degree of denial and resistance was high. Patients were approached by a researcher not actively participating in the clinical work.

Therefore, hospitalization was required to treat acute episodes and to provide tailored aftercare programs, including partial hospitalization. The duration of the intensive inpatient treatment was individualized and differently from rehabilitation programs - hospitalization did not aim to achieve full weight restoration. All individuals were diagnosed with an ED, distributed as follows: 76 with AN-R and 32 with AN-BP. Exclusion criteria were: (1) medical comorbidity preceding the AN onset (e.g., epilepsy or diabetes); (2) male gender; (3) actual 
psychosis and drug dependence. Inclusion criteria were: (1) full-criteria diagnosis of AN [15]; (2) female gender. All participants provided written informed consent according to the Ethical Committee of the Department of Neuroscience of the University of Turin.

The initial sample included 120 individuals, but 2 patients refused to be included in this study, 6 patients were male, 3 showed severe medical comorbidity and 1 was excluded because of current psychosis (paranoid brief episode in a patient affected by severe borderline personality disorder), so the sample consisted of 108 participants.

All the patients were assessed by psychiatrists with the Structured Clinical Interview for DSM-IV Axis-I Disorders (SCID-I) [38].

All participants were asked to complete psychometric tests: Body Shape Questionnaire (BSQ) to evaluate body image, Beck Depression Inventory (BDI) for a dimensional assessment of depressive symptoms, Eating Disorder Inventory-2 (EDI-2) to assess eating symptomatology, and Temperament and Character Inventory (TCI) to dimensionally assess personality. Interviews and tests have been collected during the first week of hospitalization.

Psychosomatic syndromes were diagnosed with the Structured Interview for DCPR [39].

\section{The body shape questionnaire}

The BSQ [40] is a 34-item self-report questionnaire that assesses body image and concerns about body shape. The participants have to respond to items regarding how they have felt about their body shape in the last few weeks choosing among 6 degrees of severity.

The BSQ showed good internal consistency (Cronbach alpha 0.97) [41] and test-retest reliability (0.88) [42].

\section{The beck depression inventory}

The BDI [43] is a 13-item self-report questionnaire used to evaluate the severity of depressive symptoms.

The BDI demonstrated high internal consistency, with alpha coefficients of 0.86 and 0.81 for psychiatric and non-psychiatric populations, respectively [44]; Beck and Coworkers [43] did not recommend conventional testretest reliability, however Groth-Marnat [45] reported that test retest reliabilities ranged from 0.48 to 0.86 .

\section{The eating disorder inventory - 2}

The EDI-2 [46] is a self-report inventory that measures disordered eating attitudes and behaviors and personality traits common to individuals diagnosed with ED.

The test-retest reliabilities on patients with eating disorders were between 0.81 and 0.89 and on patients with other diagnoses, revealed similar correlations, ranging from a minimum of 0.75 to a maximum of 0.94 . No difference in test-retest reliability was found between the two groups of patients with eating disorders and other diagnoses. It was found a high level of internal consistency of these four scales, indicated by Cronbach's alpha values between 0.82 and 0.93 [47].

\section{The temperament and character inventory}

The TCI [48] is a 240-item self-administered questionnaire divided into 7 dimensions. Four of these dimensions assess temperament (Novelty Seeking [NS], Harm Avoidance [HA], Reward Dependence [RD] and Persistence [P]). The other 3 dimensions of the TCI assess character, defined as the overall personality traits acquired through experience (Self-directedness [SD], Cooperativeness [C], and Self-transcendence [ST]).

Cronbach alpha values for the TCI scales ranged from 0.60 to 0.85 for the temperament scales and from 0.82 to 0.87 for the character scales. Test-retest correlations ranged from 0.52 to 0.72 for temperament and from 0.52 to 0.71 for character dimentions [49].

\section{The diagnostic criteria for psychosomatic research}

The DCPR are a diagnostic and conceptual framework consisting of both clinical syndromes and personality concepts used to translate psychosocial variables derived from Psychosomatics into operational instruments able to identify individual patients in psychosomatic and behavioural medicine [33]. A structured interview was developed to assess the presence of the 12 syndromes: health anxiety, irritable mood, demoralization, illness denial, alexithymia, type A behavior, thanatophobia, disease phobia, functional somatic symptoms secondary to a psychiatric disorder, persistent somatization, conversion syndrome, and anniversary reaction [39,50]. The DCPR syndromes can be identified using an interview composed of 58 questions with yes or no answers [50]. Their overlap rates with DSM-IV diagnoses showed that the DCPR syndromes were able to identify psychological dimensions that do not meet DSM-IV criteria [39]. The DCPR were developed also to provide clinicians with operational criteria for psychosomatic syndromes to overcome the limitations shown by the most often diagnosed disorders in medical settings [39].

The Structured Interview for DCPR showed excellent interrater reliability with kappa values ranging from 0.69 to 0.97 [51]. It showed also good correlations with dimensional instruments for the assessment of psychosocial distress such as the Toronto Alexithymia Scale [52,53], the Psychosocial Index [54], and the General Health Questionnaire [55].

\section{Statistical analysis}

For statistical analysis, we used the Statistical Package for Social Sciences (SPSS 13.0 Application Guide. Chicago: SPSS, Inc., 2004). Descriptive statistics were computed. Categorical data were compared using the Chi-square test, 
and continuous data were analysed using the $t$-test for independent samples.

Subsequently, a two-step cluster analysis was performed to gather cases into separate groups of patients with similar characteristics. The variables we considered to group participants were: DCPR syndromes, AN subtypes, Body Mass Index (BMI), duration of illness and age.

The two-step cluster method is a scalable cluster analysis algorithm designed to manage heterogeneous data sets. It can handle both continuous and categorical variables. The two steps are: 1) pre-cluster the cases into many small sub-clusters; and 2) cluster the sub-clusters resulting from pre-cluster step into the desired number of clusters. The log-likelihood distance measure was used, with participants assigned to the cluster leading to the largest likelihood.

A defined number of clusters was not defined a priori. Solution was found with the Bayesian Information Criterion.

Then we compared the groups: categorical data were compared using the Chi-square test, and continuous data were analysed using ANOVA and post hoc $t$-test for independent samples.

A level of significance of alpha $<0.05$ was considered.

\section{Results}

\section{Sociodemographic and clinical features of the sample}

Table 1 shows sociodemographic and clinical characteristics of the sample. AN-BP individuals were characterized by older age and longer duration of illness.

All groups did not differ regarding sociodemographic variables.

\section{Psychiatric assessment}

AN-BP patients reported higher scores on the TCI as regards NS and ST dimensions, on the EDI- 2 scores in bulimia, asceticism, impulsiveness, and social insecurity scales, and on the BDI. BSQ scores were very similar between AN-R and AN-BP (see Table 1).

\section{Diagnostic criteria for psychosomatic research}

The $6.4 \%$ of AN patients (6.6\% AN-R; $6.1 \%$ AN-BP) showed no psychosomatic syndromes, 46.8\% from 1 to 3 psychosomatic syndromes (51.3\% AN-R; 36.4\% AN-BP), and $46.8 \%$ of participants more than 3 psychosomatic syndromes (42.1\% AN-R; 57.5\% AN-BP). No differences were found between $\mathrm{AN}-\mathrm{R}$ and $\mathrm{AN}-\mathrm{BP}$ subgroups (Chi-Square 2.286, $\mathrm{p}<0.319$ ).

Illness denial (63\%) and alexithymia (54.6\%) were the most common DCPR syndromes; in fact, they were found in more than $50 \%$ of the whole AN sample. See Table 2 for details of DCPR syndromes.

The two-step cluster analysis individuated three mutually exclusive groups.
1. The first group was the largest $(N=53)$ and it was composed by a larger number of AN-R individuals than the second group. In this group the DCPR syndromes were generally significantly less represented than in the other two groups. The most frequent syndromes were denial of illness and alexithymia (see Table 3). This cluster was labelled as moderate psychosomatic group.

As regards clinical and assessment comparisons among groups see Table 4 .

2. The second cluster $(\mathrm{N}=28)$ showed a higher BMI. In this group AN-BP patients were more frequently found than in the other two groups. DCPR syndromes were common in this group: in particular, it was characterized by higher levels of thanatophobia, conversion symptoms and anniversary reaction; they were significantly higher than both other groups. This cluster was labelled as somatization group (see Table 3 ).

As regards clinical and assessment comparisons among groups see Table 4.

3. In the third group $(\mathrm{N}=27)$ AN-R patients were more represented when compared to the second group. DCPR syndromes in this group were extremely frequent: more than $85 \%$ of the patients showed health anxiety, illness denial, irritability, and demoralization. All patients in this group reported the alexithymia syndrome. This group was labelled as severe psychosomatic group (see Table 3 ).

As regards clinical and assessment comparisons among groups, the third group showed a longer duration of illness than group 1 (see Table 4).

Although there was no statistical significance, the first group showed shorter hospitalizations than both other groups (days of hospitalization: $29.3 \pm 15.5$ vs $32.8 \pm 28.8$ vs $32.6 \pm 27.9 ; \mathrm{df}=2, \mathrm{~F} 0.291$ ) with a shorter range between maximum and minimum duration (days of hospitalization: $3-90$ vs $9-128$ vs $12-160)$.

\section{Discussion}

\section{DCPR and AN}

This study aimed to assess on a sample of AN inpatients the comorbidity with psychosomatic syndromes using the DCPR [50].

The great majority of the sample reported a psychosomatic syndrome $(93.6 \%)$ and almost half of the sample (46.8\%) showed more than three comorbid psychosomatic syndromes, confirming the relevance of psychosomatic factors in ED [4,6], even higher than in medically ill 
Table 1 Sociodemographic and clinical features of the sample

\begin{tabular}{|c|c|c|c|c|c|}
\hline & $\begin{array}{c}\text { AN-R } \\
(N=76)\end{array}$ & $\begin{array}{l}\text { AN-BP } \\
(\mathrm{N}=32)\end{array}$ & $\begin{array}{l}\text { Total sample } \\
\qquad(\mathrm{N}=108)\end{array}$ & Chi-square/t & $\mathbf{p}$ \\
\hline Married (\%) & 12 & 14 & 13 & 0.041 & 0.839 \\
\hline Living alone (\%) & 6 & 10 & 9 & 0.211 & 0.644 \\
\hline Occupation (\%) & 22 & 28 & 24 & 0.240 & 0.624 \\
\hline Age $($ mean $\pm S D)$ & $26.1 \pm 9.1$ & $30.7 \pm 8.9$ & $27.4 \pm 9.2$ & -2.477 & 0.016 \\
\hline Years of education (mean \pm SD) & $12.9 \pm 2.6$ & $13.4 \pm 3.1$ & $13.1 \pm 2.6$ & -0.479 & 0.637 \\
\hline Body Mass Index (mean \pm SD) & $14.8 \pm 2.4$ & $15.2 \pm 3.3$ & $14.9 \pm 2.7$ & -0.865 & 0.392 \\
\hline Number of previous outpatient treatments (mean \pm SD) & $0.6 \pm 0.8$ & $0.7 \pm 0.9$ & $0.6 \pm 0.9$ & -0.364 & 0.718 \\
\hline Duration of illness (years, mean \pm SD) & $7.8 \pm 8.2$ & $12.4 \pm 8.4$ & $9.1 \pm 8.5$ & -2.652 & 0.009 \\
\hline Age of onset (years, mean \pm SD) & $18.3 \pm 6.1$ & $18.2 \pm 5.2$ & $18.3 \pm 5.8$ & -0.072 & 0.942 \\
\hline Number of hospitalizations in the previous year (mean $\pm \mathrm{SD}$ ) & $1.1 \pm 1.7$ & $1.92 \pm 3.4$ & $1.4 \pm 2.4$ & -1.046 & 0.302 \\
\hline \multicolumn{6}{|l|}{$\mathrm{TCl}$} \\
\hline Novelty seeking & $16.3 \pm 5.7$ & $19.4 \pm 6.1$ & & -2.401 & 0.018 \\
\hline Harm avoidance & $23.4 \pm 11.3$ & $21.5 \pm 8.0$ & & 0.849 & 0.398 \\
\hline Reward dependence & 14. \pm 3.9 & $12.5 \pm 4.5$ & & 1.762 & 0.081 \\
\hline Persistence & $6.4 \pm 9.6$ & $5.2 \pm 2.7$ & & 0.663 & 0.509 \\
\hline Self-directedness & $23.8 \pm 9.7$ & $20.1 \pm 7.5$ & & 1.840 & 0.069 \\
\hline Cooperativeness & $31.0 \pm 7.6$ & $29.4 \pm 7.3$ & & 0.999 & 0.320 \\
\hline Self-trascendence & $12.6 \pm 6.5$ & $15.8 \pm 5.9$ & & 2.346 & 0.021 \\
\hline \multicolumn{6}{|l|}{ EDI-2 } \\
\hline Drive for thinness & $10.9 \pm 7.6$ & $10.2 \pm 6.9$ & & 0.385 & 0.701 \\
\hline Bulimia & $2.5 \pm 3.7$ & $6.1 \pm 6.3$ & & -3.516 & 0.001 \\
\hline Body dissatisfaction & $12.2 \pm 6.7$ & $13.7 \pm 7.7$ & & -0.910 & 0.365 \\
\hline Ineffectiveness & $9.6 \pm 8.0$ & $11.9 \pm 8.2$ & & -1.261 & 0.210 \\
\hline Perfectionism & $5.3 \pm 4.3$ & $6.6 \pm 4.6$ & & -1.248 & 0.215 \\
\hline Interpersonal distrust & $6.7 \pm 5.4$ & $8.1 \pm 5.7$ & & -1.135 & 0.259 \\
\hline Interoceptive awareness & $10.4 \pm 7.9$ & $12.5 \pm 9.1$ & & -1.130 & 0.261 \\
\hline Maturity fears & $7.4 \pm 5.3$ & $8.4 \pm 6.3$ & & -0.747 & 0.457 \\
\hline Asceticism & $6.9 \pm 4.7$ & $9.7 \pm 6.4$ & & -2.332 & 0.022 \\
\hline Impulse regulation & $5.9 \pm 6.1$ & $9.5 \pm 7.4$ & & -2.504 & 0.014 \\
\hline Social insecurity & $7.5 \pm 5.1$ & $10.3 \pm 5.6$ & & -2.359 & 0.020 \\
\hline BSQ & $103.1 \pm 42.1$ & $103.2 \pm 48.3$ & & -0.006 & 0.995 \\
\hline BDI & $14.8 \pm 7.5$ & $17.0 \pm 8.0$ & & -1.259 & 0.211 \\
\hline
\end{tabular}

Legend:

AN-R: Anorexia Nervosa Restricting type.

AN-BP: Anorexia Nervosa Binge-Purging type.

$\mathrm{TCl}$ : Temperament and Character Inventory.

EDI-2: Eating Disorder Inventory-2.

BSQ: Body Dissatisfaction Questionnaire.

BDI: Beck Depression Inventory.

patients [32]. Such a high frequency of psychosomatic syndromes can be due both to the exaggerated focusing on the body in AN [56,57] and to all those psychic alterations leading to somatic ones and vice versa. This spiral mechanism could play a key-role in both maintaining the disorder [8,9] and triggering the onset of psychosomatic syndromes, particularly in severe and acute patients like those of this study.

Analising each syndrome, it should be noted that two psychosomatic syndromes (illness denial and alexithymia) were diagnosed in more than $50 \%$ of AN patients and that they were both significantly represented in all clusters of 
Table 2 Psychosomatic diagnoses: percentages of affected patients for each diagnosis

\begin{tabular}{|c|c|c|c|c|c|}
\hline & $\begin{array}{l}\text { AN-R } \\
\%(N)\end{array}$ & $\begin{array}{l}\text { AN-BP } \\
\%(N)\end{array}$ & $\begin{array}{c}\text { Total sample } \\
\%(\mathrm{~N})\end{array}$ & Chi-square & $p$ \\
\hline Illness denial & $61.8 \%(47)$ & $65.6 \%(21)$ & $63 \%(68)$ & 0.138 & 0.710 \\
\hline Alexithymia & $52.6 \%(40)$ & $59.4 \%(19)$ & $54.6 \%(59)$ & 0.413 & 0.520 \\
\hline Demoralization & $43.4 \%(33)$ & $62.5 \%(20)$ & $49.1 \%(53)$ & 3.280 & 0.071 \\
\hline Functional symptoms & $38.2 \%(29)$ & $50 \%(16)$ & $41.7 \%(45)$ & 1.299 & 0.254 \\
\hline Type A behaviour & $35.5 \%(27)$ & $43.8 \%(14)$ & $38 \%(41)$ & 0.647 & 0.421 \\
\hline Irritable mood & $30.3 \%(23)$ & $50 \%(16)$ & 36.1 (39) & 3.802 & 0.051 \\
\hline Conversion symptom & $21.1 \%(16)$ & $28.1 \%(9)$ & $23.1 \%(25)$ & 0.633 & 0.426 \\
\hline Health anxiety & $25 \%(19)$ & $18.8 \%(6)$ & $23.1 \%(25)$ & 0.494 & 0.482 \\
\hline Anniversary reaction & $7.9 \%(6)$ & $18.8 \%(6)$ & $11.1 \%(12)$ & 2.687 & 0.101 \\
\hline Persistent somatization & $9.2 \%(7)$ & $12.5 \%(4)$ & $10.2 \%(11)$ & 0.266 & 0.606 \\
\hline Disease phobia & $5.3 \%(4)$ & $12.5 \%(4)$ & $7.4 \%(8)$ & 1.719 & 0.190 \\
\hline Thanatophobia & $6.6 \%(5)$ & $6.3 \%(2)$ & $6.5 \%(7)$ & 0.004 & 0.949 \\
\hline
\end{tabular}

this study. It is noteworthy that both syndromes are wellknown factors involved in both maintaining the disorder and in resistance to treatment. These data are in line with literature since these two syndromes have been suggested as possible psychosomatic key-elements for some diagnostic or psychopathological factors $[58,59]$.

Illness denial - the most frequent syndrome - represents an important factor to explain patients' obstinate treatment refusal [60], high rates of drop-out [61], and their wellknown difficulty to maintain a trusting relationship with their psychotherapist $[57,60]$.
Alexithymia describes ED patients' emotive inability and it is considered more trait rather than state-dependent in ED pathogenesis [62]. Eating symptomatology has been suggested to represent a strategy to avoid emotions [63] and the impairment in recognizing and expressing them could generate body symptoms as "concretized metaphors" describing a psychic equivalence between physical and psychic reality with concretized emotions as a result [35]. As Skårderud states "Concretized metaphors refer to instances where the metaphors are not experienced as indirect expressions showing something thus mediated,

Table 3 Psychosomatic diagnostic categories within each cluster

\begin{tabular}{|c|c|c|c|c|c|}
\hline & $\begin{array}{l}\text { Moderate psychosomatic group } \\
\qquad(\mathrm{N}=53) \\
\%(\mathrm{~N})\end{array}$ & $\begin{array}{l}\text { Somatization group } \\
\qquad \begin{array}{c}(\mathrm{N}=28) \\
\%(\mathrm{~N})\end{array}\end{array}$ & $\begin{array}{l}\text { Severe psychosomatic group } \\
\qquad(\mathrm{N}=27) \\
\%(\mathrm{~N})\end{array}$ & Chi-square & $\mathrm{p}$ \\
\hline AN-BP subtype & $25 \%(8)$ & $53 \%(17)$ & $22 \%(7)$ & & \\
\hline AN-R subtype & $57 \%(44)$ & $15 \%(12)$ & $27 \%(20)$ & 15.58 & 0.001 \\
\hline Health anxiety & $0 \%(0)$ & $7 \%(2)$ & $85 \%(23)$ & 77.59 & 0.001 \\
\hline Disease phobia & $0 \%(0)$ & $14 \%(4)$ & $15 \%(4)$ & 8.18 & 0.017 \\
\hline Thanatophobia & $2 \%(1)$ & $21 \%(6)$ & $0 \%(0)$ & 13.85 & 0.002 \\
\hline Illness denial & $52 \%(27)$ & $54 \%(15)$ & $93 \%(15)$ & 13.88 & 0.001 \\
\hline Functional symptoms & $15 \%(8)$ & $64 \%(18)$ & $70 \%(19)$ & 29.74 & 0.001 \\
\hline Persistent somatization & $6 \%(3)$ & $21 \%(6)$ & $7 \%(2)$ & 5.16 & 0.076 \\
\hline Conversion symptom & $12 \%(6)$ & $60 \%(17)$ & $7 \%(2)$ & 29.716 & 0.001 \\
\hline Anniversary reaction & $0 \%(0)$ & $39 \%(11)$ & $0 \%(0)$ & 34.59 & 0.001 \\
\hline Type A behaviour & $19 \%(10)$ & $57 \%(16)$ & $56 \%(15)$ & 15.60 & 0.001 \\
\hline Irritable mood & $2 \%(1)$ & $54 \%(15)$ & $85 \%(23)$ & 57.99 & 0.001 \\
\hline Demoralization & $19 \%(10)$ & $61 \%(17)$ & $96 \%(26)$ & 44.12 & 0.001 \\
\hline Alexithymia & $38 \%(20)$ & $39 \%(11)$ & $100 \%(27)$ & 30.51 & 0.001 \\
\hline
\end{tabular}

Legend:

AN-R: Anorexia Nervosa Restricting type.

AN-BP: Anorexia Nervosa Binge-Purging type. 
Table 4 Comparison of clinical and assessment variables among groups

\begin{tabular}{|c|c|c|c|c|c|c|c|c|}
\hline & $\begin{array}{c}\text { Moderate } \\
\text { psychosomatic group } \\
\text { Group } 1(\mathrm{~N}=53) \\
\text { mean } \pm \mathrm{SD}\end{array}$ & $\begin{array}{l}\text { Somatization } \\
\text { group } \\
\text { Group } 2(\mathrm{~N}=28) \\
\text { mean } \pm \mathrm{SD}\end{array}$ & $\begin{array}{c}\text { Severe } \\
\text { psychosomatic group } \\
\text { Group } 3(\mathrm{~N}=27) \\
\text { mean } \pm \mathrm{SD}\end{array}$ & $F$ & F Sign & $\begin{array}{l}\text { p Group } 1 \text { vs } \\
\text { Group } 2\end{array}$ & $\begin{array}{l}\text { p Group } 2 \text { vs } \\
\text { Group } 3\end{array}$ & $\begin{array}{l}\text { p Group } 1 \text { vs } \\
\text { Group } 3\end{array}$ \\
\hline BMI & $14.6 \pm 1.9$ & $16.1 \pm 3.3$ & $14.1 \pm 2.7$ & 4.88 & 0.009 & 0.037 & 0.012 & 1.000 \\
\hline \multicolumn{9}{|l|}{ EDI-2 } \\
\hline Bulimia & $2.8 \pm 4.7$ & $6.3 \pm 6.1$ & $2.5 \pm 2.4$ & 5.31 & 0.007 & 0.010 & 0.021 & 1.000 \\
\hline \multicolumn{9}{|l|}{ Body } \\
\hline dissatisfaction & $11.12 \pm 7$ & $16.8 \pm 6.7$ & $12 \pm 5.6$ & 6.0 & 0.004 & 0.003 & 0.046 & 1.000 \\
\hline Ineffectiveness & $7.5 \pm 7.1$ & $15.9 \pm 8.5$ & $11.0 \pm 6.9$ & 10.11 & 0.001 & 0.001 & 0.089 & 0.189 \\
\hline Perfectionism & $4.6 \pm 3.6$ & $7.4 \pm 4.7$ & $6.4 \pm 5.1$ & 3.84 & 0.025 & 0.030 & 1.000 & 0.296 \\
\hline \multicolumn{9}{|l|}{ Interoceptive } \\
\hline awareness & $8.7 \pm 7.3$ & $17.8 \pm 8.1$ & $10 \pm 6.8$ & 12.27 & 0.001 & 0.001 & 0.002 & 1.000 \\
\hline Asceticism & $5.9 \pm 4.1$ & $11.2 \pm 6.4$ & $8.4 \pm 5.1$ & 8.85 & 0.001 & 0.001 & 0.201 & 0.152 \\
\hline Impulsiveness & $4.2 \pm 5.1$ & $13.8 \pm 7$ & $6.6 \pm 4$ & 24.5 & 0.001 & 0.001 & 0.001 & 0.251 \\
\hline $\begin{array}{l}\text { Social } \\
\text { insecurity }\end{array}$ & $6.5 \pm 4.9$ & $12 \pm 5.7$ & $8.6 \pm 4.2$ & 9.5 & 0.001 & 0.001 & 0.078 & 0.277 \\
\hline BSQ & $89 \pm 34.2$ & $140.6 \pm 40.4$ & $93.2 \pm 42.8$ & 8.33 & 0.001 & 0.001 & 0.006 & 1.000 \\
\hline \multicolumn{9}{|l|}{ TCl } \\
\hline $\begin{array}{l}\text { Self- } \\
\text { Directedness }\end{array}$ & $24.8 \pm 9.9$ & $16.6 \pm 5.2$ & $24.2 \pm 8.2$ & 8.19 & 0.001 & 0.001 & 0.009 & 1.000 \\
\hline $\mathrm{BDI}$ & $12.3 \pm 6.9$ & $21.9 \pm 6.6$ & $14.7 \pm 5.5$ & 16.71 & 0.001 & 0.001 & 0.002 & 0.569 \\
\hline $\begin{array}{l}\text { Duration of } \\
\text { illness (years) }\end{array}$ & $7.9 \pm 8.8$ & $7.8 \pm 6.1$ & $12.6 \pm 9.1$ & 3.25 & 0.043 & 1.000 & 0.108 & 0.049 \\
\hline
\end{tabular}

Legend:

BMI: Body Mass Index.

EDI-2: Eating Disorder Inventory-2.

BSQ: Body Shape Questionnaire.

TCl: Temperament and Character Inventory.

BDI: Beck Depression Inventory.

but they are experienced as direct and bodily revelations of a concrete reality. There is an immediate equivalence between bodily and emotional experience" [35].

Comparing descriptive data of the whole sample to those of our previous study on ED outpatients [13], the current sample differs as regards the higher frequency of type A behavior. This different result can be due to different sampling criteria: in fact, we previously included outpatients and individuals affected also by Binge Eating Disorder. It is indeed largely known that AN patients compared to other ED individuals - behave in a more controlled and perfectionistic way [64]. Moreover, the present sample included AN inpatients in an emergency phase: it could also be hypothesized that type A behavior diagnostic category is less stable in time and more statedependent than other categories.

The rates of psychosomatic syndromes obtained by using DCPR (see Table 2) did not differ significantly between AN subtypes. In AN-BP patients it could be also observed a higher prevalence of demoralization, even if not significant. These findings are in line with previous data in literature reporting a more frequent comorbid depressive symptomatology and anger dyscontrol in this subtype of AN $[65,66]$.

\section{DCPR and clusters}

The second aim of this study consisted in grouping the sample into more specific clusters to better characterize the link between psychosomatic syndromes and DCPR. Compared with limited DSM-IV ED diagnoses, clusters allow a more clearly differentiated characterization of patients subgroups on a broad range of features. Previous researches considering clusters had a clinical utility $[67,68]$. In our study, a cluster analysis allowed to identify specific association patterns between AN and psychosomatic syndromes. It is well-known that ED can also be subdivided according to personality features in different ways [69-71]. It is possible that different personality styles associated to ED can correspond to different psychosomatic clusters. In fact, AN patients who are mainly characterized by a perfectionistic and inhibited style are more represented by cluster 1 whilst AN-BP, 
more disinhibited and impulsive are mostly represented in cluster 2. Therefore, the use of psychosomatic clusters reinforces the idea of different personality styles and psychopathological variability in AN. From a clinical standpoint, to identify patients on the bases of their problems of somatization versus personality and alexithymia could mean to use different treatments, as debated below.

The TCI provided less data than expected as regards clusters mostly about temperament dimensions. However, it is of interest that the somatization group showed lower Selfdirectedness (SD) than other groups. Since SD quantifies the extent to which an individual is responsible, reliable, resourceful, goal-oriented, and self-confident it is noteworthy that the group showing a more immature character expresses distress through corporeality. Maybe this group has less resources to verbalize problems; therefore, therapy should address such an impairment: psychotherapy needs to consider the possible hindrance represented by the poorer expressive tools of this subgroup.

The cluster analysis individuated three clusters: moderate psychosomatic, somatization, and severe psychosomatic group.

The first group represented about a half of the sample and the psychosomatic syndromes were relatively scarcely represented (6 syndromes out of 12 were lower than $10 \%$; see Table 4). The most represented syndromes of the first group were illness denial (52\%) and alexithymia (38\%) since these syndromes were highly represented also in other groups it could be raised the hypothesis that such features can be shared by AN individuals. It is noteworthy that this group seemed to be mostly represented by AN-R individuals (85\%), with less severe eating symptomatology than group 2 and with shorter duration of illness than group 3. Given the cross-sectional design of this study it cannot be clarified if less psychosomatic syndromes are causes or consequences of severity of illness or duration of illness. However, it is clear that a smaller number of psychosomatic syndromes mean a better clinical condition at the moment of assessment. Still, even though the datum is not statistically significant, this group required shorter hospitalizations than the other groups.

The second group (somatization group) assembled patients with severe eating psychopathology, mostly AN$\mathrm{BP}$, well-known feature influencing negatively prognosis [72]. In spite of higher BMI, this finding is not in contradiction with a more severe psychopathology; in fact, BMI is representative of the somatic - rather than psychiatric - clinical severity [73]. Patients seemed to show higher character immaturity than the other groups: also this element indicates higher severity [66].

Moreover, in this group was found high depressive symptomatology, generally associated to the severity of eating psychopathology [66]. The majority of patients in this group reported psychosomatic problems (6 psychosomatic syndromes have been found in more than 50\% of the sample; see Table 3). In particular, the clinical severity of this cluster was associated with thanatophobia (found almost exclusively in this group), somatization area (persistent somatization, conversion symptom and anniversary reaction) and type A behavior. These syndromes could be indeed considered as severity indexes of ED.

Thanatophobia can be associated to both a more severe psychiatric comorbidity and the awareness of higher risks of death due to hypokalemia, condition linked to purging behaviors [73].

Somatization has not been well deepened in the ED population, even if some studies have recently described the relationship between functional symptomatology and $\mathrm{ED}$, in particular the gastroenteric functional symptoms $[74,75]$. From a clinical standpoint, it could be difficult to diagnose as organic or functional a gastrointestinal disease referred by ED patients; anyway it is well-known that ED patients' body sensations - often inappropriately experienced - can influence the disease and its course [11]. Moreover, in this subgroup were also clearly represented some conversion symptoms, only sporadically discussed in AN patients [76,77]. Hence, it should be considered that for some AN patients - as in this cluster body language can be a further sign of their clinical severity, requiring a clinical approach specifically tailored to these conversion aspects, often a neglected issue in AN treatment.

Still, the high frequency of type A behavior (54\%) in this group could be strictly related to both need of control and perfectionism, core elements and severity indexes of AN [64].

The third group was extremely characterized by psychosomatic aspects (6 syndromes have been found in more than $70 \%$ of the sample; see Table 4). In particular, in this group have been found high percentages of health anxiety (85\%) - in contrast with the other groups - and high percentages of psychosomatic syndromes of those psychological factors influencing illness vulnerability.

Moreover, AN individuals of this group showed a duration of illness significantly higher than the first group.

Anxiety traits and symptoms are widely known in a subgroup of AN patients and they can influence negatively their prognosis [78]. It is noteworthy that in this subgroup the DCPR health anxiety syndrome is associated to a longer duration of the illness. Health anxiety could be indeed explained by a heavier burden of disease after many years of AN.

Finally, almost all patients in this group deny illness (93\%), hardly recognize and express their feelings (100\%), and are frequently irritated (85\%) or demoralized (96\%). From a clinical standpoint, it should be noted that feelings of loss of hope and anger lower patients' motivation, key 
element in ED treatments [79,80]. Future longitudinal researches should investigate if early demoralization can predict early drop-out, worse long-term outcome and consecutively entail a longer duration of ED or if it is the long duration of illness to make patients more alexithymic, irritable, and demoralized. It should be noted that this subgroup highlights that long-standing patients show more psychosomatic problems and that the latter can further strengthen the eating vicious circle [8]. Probably, AN treatments should mainly address the "give-up syndrome" that can arise considering patients' low motivation and previously failed treatments [8]. This intervention could be preliminary to the specific ED treatment and it could help not to thwart clinical efforts.

\section{Conclusions}

This study shows several limitations. First, it is crosssectional and so it is not possible to individuate to what extent DPCR in AN is state-independent or stable in time. Second, the presence of organic symptomatology in AN individuals could be a bias overestimating or underestimating some syndromes as persistent functional symptoms. Third, the considered sample is large but including only AN inpatients and so the results cannot be generalized to less severe patients. Still, more AN-R than AN-BP patients were included and it would be interesting to replicate DCPR evaluation also in other ED Centres and with a comparison group. From a statistical standpoint, corrective measures for the post-hoc test (e.g., the Bonferroni correction) were not used. Finally, a limitation of this study is the lack of a control group. However, comparing our data to the ones in literature on the general population [30], it should be noted that ED patients are more often affected by psychosomatic syndromes. When compared to depressed patients [81] the percentages of psychosomatic syndromes did not differ but illness denial and alexithymia were less represented in depressed patients that in $\mathrm{AN}$, raising the hypothesis of different psychosomatic patterns among psychiatric diagnoses.

Considering the aforementioned limitations, this work highlights the role of psychosomatic factors - neglected topic in the last decades of ED research $[9,13]$ - in AN. The study provides support to the clinical utilization of DCPR to assess patients with a more complex approach. Still, the identification of clusters could have relevant therapeutic implications. It is well-known in literature that those patients who are highly alexithymic receive overall more treatments - and significantly more antidepressants rather than psychotherapy - than those without these traits [82]. The cluster showing higher alexithymia represents instead a caveat as regards undergoing psychotherapy. Moreover, somatization issues in ED - as reported in cluster 2 - represent a quite new research field as de- monstrated by the current dearth of studies; lived corporeality [36] should be addressed more in therapy with patients of this group. Given their common comorbidity with borderline personality traits - usually highlighting themes of somatic preoccupation and somatization disorder [83] -, AN-BP patients often report such features, which should be specifically considered in therapy.

The study reports indeed that the majority of $\mathrm{AN}$ patients shows psychosomatic elements and also that such elements are relevant for both patients' assessment and treatments. This can support the introduction of a more complex clinical practice able to provide tailored treatments [9] in conjunction with the categorical diagnostic system reporting patients - eventually deceptively - as similar [31]. In particular, alexithymia and illness denial resulted to be common syndromes in AN individuals: these syndromes well describe some core factors of ED patients' resistance to treatments $[59,84]$ and drop-out [61].

Psychosomatic syndromes allow to identify subgroups of patients with different features; particularly, we found that $25 \%$ of the AN sample reported relevant psychosomatic problems probably associated to longer duration of illness. Clinicians should carefully consider these elements to provide more effective treatments and to achieve more compliance to therapy. Further longitudinal studies are warranted to shed light on psychosomatic syndromes and their utilization in clinical practice.

\section{Competing interests}

The authors have no competing interests to declare.

\section{Authors' contributions}

A-DG designed the study and wrote the majority of the paper; DN revised the manuscript critically; NB contributed to write the paper; GC contributed to write the paper and edited the manuscript; ME revised and translated the paper; AF revised the manuscript critically; FS gave the final approval of the version to be published. All authors read and approved the final manuscript.

Received: 24 May 2012 Accepted: 3 January 2013

Published: 9 January 2013

\section{References}

1. Ey H, Bernard P, Brisset C: Manuel de psychiatrie. Paris: Masson; 1960.

2. Haynal A, Pasini W: Medicina psicosomatica. Milano: Masson; 1979.

3. Minuchin S, Rosman BL, Baker L: Psychosomatic Families. Cambridge: Harvard University Press; 1978.

4. Parling $T$, Mortazavi $M$, Ghaderi A: Alexithymia and emotional awareness in anorexia nervosa: time for a shift in the measurement of the concept? Eat Behav 2010, 11(4):205-210.

5. Fox JR, Froom K: Eating disorders: a basic emotion perspective. Clin Psychol Psychother 2009, 16(4):328-335.

6. Tagay S, Schlegl S, Senf W: Traumatic events, posttraumatic stress symptomatology and somatoform symptoms in eating disorder patients. Eur Eat Disord Rev 2010, 18(2):124-132.

7. Keys A, Brozek J, Henschel A, Mickelesen O, Taylor HL: The Biology of Human Starvation. Minneapolis: University of Minnesota Press; 1950.

8. Kaye W: Eating disorders: hope despite mortal risk. Am J Psychiatry 2009, 166(12):1309-1311. 
9. Fassino S: Psychosomatic approach is the new medicine tailored for patient personality with a focus on ethics, economy, and quality. Panminerva Med 2010, 52(3):249-264.

10. Fassino S, Pierò A, Gramaglia C, Abbate-Daga G: Clinical, psychopathological and personality correlates of interoceptive awareness in anorexia nervosa, bulimia nervosa and obesity. Psychopathology 2004, 37(4):168-174.

11. Pollatos $\mathrm{O}$, Kurz AL, Albrecht J, Schreder T, Kleemann AM, Schöpf $V$, Kopietz R, Wiesmann M, Schandry R: Reduced perception of bodily signals in anorexia nervosa. Eat Behav 2008, 9(4):381-388.

12. Kaye $W H$, Fudge $J$, Paulus $M$ : New insights into symptoms and neurocircuit function of anorexia nervosa. Nat Rev Neurosci 2009 10(8):573-584

13. Fassino S, Daga GA, Pierò A, Delsedime N: Psychological factors affecting eating disorders. Adv Psychosom Med 2007, 28:141-168.

14. Fava GA, Fabbri S, Sirri L, Wise TN: Psychological factors affecting medical condition: a new proposal for DSM-V. Psychosomatics 2007, 48(2):103-111.

15. American Psychiatric Association: Diagnostic and Statistical Manual of Mental Disorders DSM-IV-TR. Fourthth edition. Washington: American Psychiatric Publishing Inc; 2000

16. Fava GA, Wise TN: Issues for DSM-V: psychological factors affecting either identified or feared medical conditions: a solution for somatoform disorders. Am J Psychiatry 2007, 164(7):1002-1003.

17. Wise TN: Diagnostic criteria for psychosomatic research are necessary for DSM V. Psychother Psychosom 2009, 78(6):330-332.

18. Sirri L, Fabbri S, Fava GA, Sonino N: New strategies in the assessment of psychological factors affecting medical conditions. J Pers Assess 2007, 89(3):216-228

19. Noyes R, Stuart S, Watson DB, Langbehn DR: Distinguishing between hypochondriasis and somatization disorder: a review of the existing literature. Psychother Psychosom 2006, 75(5):270-281

20. Pilowsky I: Abnormal illness behaviour. Chichester, England: Wiley; 1997.

21. Fava GA, Sonino N: Psychosomatic assessment. Psychother Psychosom 2009, 78(6):333-341.

22. Fava GA, Offidani E: Psychosomatic renewal of health care. Panminerva Med 2010, 52(3):239-248.

23. Porcelli $P$, De Carne M, Fava GA: Assessing somatization in functional gastrointestinal disorders: integration of different criteria. Psychother Psychosom 2000, 69(4):198-204.

24. Fava GA, Mangelli L, Ruini C: Assessment of psychological distress in the setting of medical disease. Psychother Psychosom 2001, 70(4):171-175

25. Grandi S, Fabbri S, Tossani E, Mangelli L, Branzi A, Magelli C: Psychological evaluation after cardiac transplantation: the integration of different criteria. Psychother Psychosom 2001, 70(4):176-183.

26. Rafanelli C, Roncuzzi R, Finos L, Tossani E, Tomba E, Mangelli L, Urbinati S, Pinelli G, Fava GA: Psychological assessment in cardiac rehabilitation. Psychother Psychosom 2003, 72(6):343-349

27. Sonino N, Navarrini C, Ruini C, Ottolini F, Paoletta A, Fallo F, Boscaro M, Fava GA: Persistent psychological distress in patients treated for endocrine disease. Psychother Psychosom 2004, 73(2):78-83.

28. Mangelli L, Bravi A, Fava GA, Ottolini F, Porcelli P, Rafanelli C, Rigatelli M, Sonino N: Assessing somatization with various diagnostic criteria. Psychosomatics 2009, 50(1):38-41.

29. Porcelli P, Rafanelli C: Criteria for psychosomatic research (DCPR) in the medical setting. Curr Psychiatry Rep 2010, 12(3):246-254.

30. Mangelli L, Semprini F, Sirri L, Fava GA, Sonino N: Use of the diagnostic criteria for psychosomatic research (DCPR) in a community sample. Psychosomatics 2006, 47(2):143-146.

31. Fava GA, Porcelli P, Rafanelli C, Mangelli L, Grandi S: The spectrum of anxiety disorders in the medically ill. J Clin Psychiatry 2010, 71(7):910-914

32. Guidi J, Fava GA, Picardi A, Porcelli P, Bellomo A, Grandi S, Grassi L, Pasquini $P$, Quartesan R, Rafanelli $C$, et al: Subtyping depression in the medically ill by cluster analysis. J Affect Disord 2011, 132(3):383-388.

33. Porcelli P, Bellomo A, Quartesan R, Altamura M, luso S, Ciannameo I, Piselli $M$, Elisei S: Psychosocial functioning in consultation-liaison psychiatry patients: influence of psychosomatic syndromes, psychopathology and somatization. Psychother Psychosom 2009,

78(6):352-358

34. Fassino $S$, Daga GA, Pierò A, Leombruni P, Rovera GG: Anger and personality in eating disorders. J Psychosom Res 2001, 51(6):757-764.
35. Skårderud F: Eating one's words, part I: 'Concretised metaphors' and reflective function in anorexia nervosa-an interview study. Eur Eat Disord Rev 2007, 15(3):163-174.

36. Stanghellini G, Castellini G, Brogna P, Faravelli C, Ricca V: Identity and eating disorders (IDEA): a questionnaire evaluating identity and embodiment in eating disorder patients. Psychopathology 2012 45(3):147-158

37. American Psychiatric Association: Treatment of patients with eating disorders, 3rd ed. Am J Psychiatry 2006, 163(Suppl):4-54.

38. First MB, Spitzer RL, Gibbon M, Williams JBW: Structured Clinical Interview for DSM IV Axis I Disorders (SCID-1), Clinician Version, Administration Booklet. Washington: American Psychiatric Publishing Inc; 1997.

39. Porcelli P, Sonino N: Psychological factors affecting medical conditions. A new classification for DSM-V. Basel: Karger; 2007

40. Cooper PJ, Taylor MJ, Cooper Z, Fairburn CG: Development and validation of the body shape questionnaire. Int J Eat Disord 1987, 6:485-494.

41. Franko DL, Jenkins A, Roehrig JP, Luce KH, Crowther JH, Rodgers RF: Psychometric properties of measures of eating disorder risk in Latina college women. Int J Eat Disord 2012, 45(4):592-596.

42. Rosen JC, Jones A, Ramirez E, Waxman S: Body shape questionnaire: studies of validity and reliability. Int J Eat Disord 1996, 20:315-319.

43. Beck AT, Ward CH, Mendelson M, Mock J, Erbaugh J: An inventory for measuring depression. Arch Gen Psychiatry 1961, 4:561-571.

44. Beck AT, Steer RA, Garbin MG: Psychometric properties of the beck depression inventory: twenty-five years of evaluation. Clin Psychol Rev 1988, 8(1):77-100.

45. Groth-Marnat G: The handbook of psychological assessment. 2nd edition. New York: John Wiley \& Sons; 1990.

46. Garner DM: Eating Disorder Inventory 2: Professional Manual. Odessa: Psychol Assess Res; 1993.

47. Thiel A, Paul T: Test-retest reliability of the eating disorder inventory 2 J Psychosom Res 2006, 61(4):567-569.

48. Cloninger CR, Svrakic DM, Przybeck TR: A psychobiological model of temperament and character. Arch Gen Psychiatry 1993, 50(12):975-990.

49. Sung SM, Kim JH, Yang E, Abrams KY, Lyoo IK: Reliability and validity of the Korean version of the temperament and character inventory. Compr Psychiatry 2002, 43:235-243.

50. Fava GA, Freyberger HJ, Bech P, Christodoulou G, Sensky T, Theorell T, Wise TN: Diagnostic criteria for use in psychosomatic research. Psychother Psychosom 1995, 63(1):1-8.

51. Galeazzi GM, Ferrari S, Mackinnon A, Rigatelli M: Interrater reliability, prevalence and relation to ICD-10 diagnoses of the diagnostic criteria for psychosomatic research in consultation-liaison psychiatry patients. Psychosomatics 2004, 45:386-393.

52. Beresnevaité M, Taylor GJ, Bagby RM: Assessing alexithymia and type a behavior in coronary heart disease patients: a multimethod approach Psychother Psychosom 2007, 76:186-192.

53. Fukunishi I, Hosaka T, Aoki T, Azekawa T, Ota A, Miyaoka H: Criterion-related validity of diagnostic criteria for alexithymia in a general hospital psychiatric setting. Psychother Psychosom 1996, 65:82-85.

54. Sonino N, Navarrini C, Ruini C, Ottolini F, Paoletta A, Fallo F, Boscaro M, Fava GA: Persistent psychological distress in patients treated for endocrine disease. Psychother Psychosom 2004, 73:78-83.

55. Picardi A, Pasquini P, Abeni D, Fassone G, Mazzotti E, Fava GA: Psychosomatic assessment of skin diseases in clinical practice. Psychother Psychosom 2005, 74:315-322.

56. Fairburn CG, Cooper Z, Doll HA, O'Connor ME, Bohn K, Hawker DM, Wales JA, Palmer RL: Transdiagnostic cognitive-behavioral therapy for patients with eating disorders: a two-site trial with 60-week follow-up. Am J Psychiatry 2009, 166(3):311-319.

57. Abbate-Daga G, Gramaglia C, Amianto F, Marzola E, Fassino S: Attachment insecurity, personality, and body dissatisfaction in eating disorders. J Nerv Ment Dis 2010, 198(7):520-524.

58. Fairburn CG: Cognitive Behavior Therapy and Eating Disorders. New York: Guilford Press; 2008.

59. Eddy KT, Dorer DJ, Franko DL, Tahilani K, Thompson-Brenner H, Herzog DB: Diagnostic crossover in anorexia nervosa and bulimia nervosa: implications for DSM-V. Am J Psychiatry 2008, 165(2):245-250.

60. Nordbø RH, Espeset EM, Gulliksen KS, Skårderud F, Geller J, Holte A: Reluctance to recover in anorexia nervosa. Eur Eat Disord Rev 2012, 20(1):60-67. 
61. Fassino S, Pierò A, Tomba E, Abbate-Daga G: Factors associated with dropout from treatment for eating disorders: a comprehensive literature review. BMC Psychiatry 2009, 9:67.

62. Oldershaw A, Hambrook D, Stahl D, Tchanturia K, Treasure J, Schmidt U: The socio-emotional processing stream in anorexia nervosa. Neurosci Biobehav Rev 2011, 35(3):970-988.

63. Wildes JE, Marcus MD: Development of emotion acceptance behavior therapy for anorexia nervosa: a case series. Int J Eat Disord 2011 44(5):421-427.

64. Bardone-Cone AM, Wonderlich SA, Frost RO, Bulik CM, Mitchell JE, Uppala S, Simonich H: Perfectionism and eating disorders: current status and future directions. Clin Psychol Rev 2007, 27(3):384-405.

65. Godart NT, Perdereau F, Rein Z, Berthoz S, Wallier J, Jeammet P, Flament MF: Comorbidity studies of eating disorders and mood disorders. Critical review of the literature. J Affect Disord 2007, 97(1-3):37-49.

66. Daga GA, Gramaglia C, Bailer U, Bergese S, Marzola E, Fassino S: Major depression and avoidant personality traits in eating disorders. Psychother Psychosom 2011, 80(5):319-320

67. Turner H, Bryant-Waugh R, Peveler R: A new approach to clustering eating disorder patients: assessing external validity and comparisons with DSM-IV diagnoses. Eat Behav 2010, 11(2):99-106.

68. Peñas-Lledó E, Jiménez-Murcia $S$, Granero R, Penelo E, Agüera Z, Alvarez-Moya E, Fernández-Aranda F: Specific eating disorder clusters based on social anxiety and novelty seeking. J Anxiety Disord 2010, 24(7):767-773

69. Fassino S, Abbate-Daga G, Amianto F, Leombruni P, Boggio S, Rovera GG: Temperament and character profile of eating disorders: a controlled study with the temperament and character inventory. Int J Eat Disord 2002, 32(4):412-425.

70. Westen D, Harnden-Fischer J: Personality profiles in eating disorders: rethinking the distinction between axis I and axis II. Am J Psychiatry 2001, 158(4):547-562.

71. Thompson-Brenner H, Eddy KT, Franko DL, Dorer DJ, Vashchenko M, Kass $A E$, Herzog DB: A personality classification system for eating disorders: a longitudinal study. Compr Psychiatry 2008, 49(6):551-560.

72. Steinhausen HC: The outcome of anorexia nervosa in the 20th century. Am J Psychiatry 2002, 159(8):1284-1293.

73. Abbate Daga G, Campisi S, Marzola E, Rocca G, Peris C, Campagnoli C, Peloso A, Vesco S, Rigardetto R, Fassino S: Amenorrhea in eating disorders: poor stability of symptom after a one-year treatment. Eat Weight Disord 2012, 17(2):e78-85.

74. Boyd C, Abraham S, Kellow J: Appearance and disappearance of functional gastrointestinal disorders in patients with eating disorders. Neurogastroenterol Motil 2010, 22(12):1279-1283.

75. Abraham S, Kellow J: Exploring eating disorder quality of life and functional gastrointestinal disorders among eating disorder patients. J Psychosom Res 2011, 70(4):372-377.

76. Nozaki T, Takao M, Takakura S, Koreeda-Arimura C, Ishido K, Yamada Y, Kawai K, Takii M, Kubo C: Psychopathological features of patients with prolonged anorexia nervosa as assessed by the Minnesota multiphasic personality inventory. Eat Weight Disord 2006, 11(2):59-65.

77. Wilhelmsson $M$, Andersson AL: An attempt at distinguishing subgroups of women with anorexia nervosa and bulimia nervosa by means of the defense mechanism technique modified (DMTm) and the eating disorder inventory (EDI). Eat Weight Disord 2005 10(3):175-186

78. Kaye WH, Bulik CM, Thornton L, Barbarich N, Masters K: Comorbidity of anxiety disorders with anorexia and bulimia nervosa. Am J Psychiatry 2004, 161(12):2215-2221.

79. Wade TD, Frayne A, Edwards SA, Robertson T, Gilchrist P: Motivational change in an inpatient anorexia nervosa population and implications for treatment. Aust N Z J Psychiatry 2009, 43(3):235-243.

80. Cockram CA, Doros G, de Figueiredo JM: Diagnosis and measurement of subjective incompetence: the clinical hallmark of demoralization. Psychother Psychosom 2009, 78(6):342-345.

81. Guidi J, Fava GA, Picardi A, Porcelli P, Bellomo A, Grandi S, Grassi L, Pasquini P, Quartesan R, Rafanelli C, Rigatelli M, Sonino N: Subtyping depression in the medically ill by cluster analysis. J Affect Disord 2011, 132(3):383-388.
82. Speranza M, Loas G, Guilbaud O, Corcos M: Are treatment options related to alexithymia in eating disorders? Results from a three-year naturalistic longitudinal study. Biomed Pharmacother 2011, 65(8):585-589.

83. Sansone RA, Sansone LA: Borderline personality: a primary care context. Psychiatry (Edgmont) 2004, 1(2):19-27.

84. Vitousek K, Watson S, Wilson GT: Enhancing motivation for change in treatment-resistant eating disorders. Clin Psychol Rev 1998, 18(4):391-420

doi:10.1186/1471-244X-13-14

Cite this article as: Abbate-Daga et al:: Psychosomatic syndromes and anorexia nervosa. BMC Psychiatry 2013 13:14.

\section{Submit your next manuscript to BioMed Central and take full advantage of:}

- Convenient online submission

- Thorough peer review

- No space constraints or color figure charges

- Immediate publication on acceptance

- Inclusion in PubMed, CAS, Scopus and Google Scholar

- Research which is freely available for redistribution 